\title{
Loneliness \& Depression: An Urban Syndrome?
}

\author{
Miss Asmita Karmakar ${ }^{1}$, Dr. Souvik Raychaudhuri ${ }^{2}$
}

\section{ABSTRACT}

Context: Depression and loneliness are distinct yet mutually reinforcing phenomena. Considering the current transitional state of society and growing urban city, the question of urban-rural differences in feelings of depression and loneliness appears to be a serious, but neglected one. Aim: The aim of the study was to determine the variations (if any) in subjective feelings of loneliness and depression across habitat (urban versus rural). Settings and Design: The sample comprised of 320 adults (160 male and 160 female) aged 20 to 38 years, among which there were two groups : the clinical group, which comprised of 160 adults (80 males and 80 females) suffering from Major Depressive Disorder and the non-clinical group, which comprised of 160 adults ( 80 males and 80 females) not suffering from any psychiatric disorder. Each group had 80 urban residents and 80 rural residents. The clinical and non-clinical groups were matched on the basis of age, education and socio-economic status. Methods and Materials: Data was collected using Beck Depression Inventory, R-UCLA Loneliness Scale. GHQ-28 was used to screen out psychiatric morbidity and select participants for the non-clinical group. Statistical Analysis: Descriptive statistical analysis and analysis of variance was conducted to see if the urban and the rural group differed significantly in their subjective feelings of depression and loneliness. Results and Conclusions: Results showed that urban participants had significantly higher subjective feelings of loneliness as well as depression than their rural counterparts, both in non-clinical and clinical groups.

Keywords: Loneliness, depression, Urban, Rural.

Loneliness may be a phenomenon that all people experience at some time at some point of their existence and is principally a temporary state that dissipates as peoples' circumstances vary (Lauder et al 2006). For some individuals however, loneliness is a continual feature (Ernst \& Cacioppo, 1999). Loneliness is synonymous with perceived social isolation which is dissimilar from objective social isolation. People can manage to survive relatively solitary lives and not feel dejected and conversely, they can survive an ostensibly a rich social life and feel lonely. Loneliness is defined as a distressing feeling that accompanies the perception that one's social needs are not being met by the magnitude or especially the quality of one's social relationships. Peplau and Perlman (1982) define loneliness as ‘Loneliness exists to the extent that a person's

\footnotetext{
${ }^{1}$ Department of Psychology, University of Calcutta

${ }^{2}$ MSc. PhD MSPA (USA), Associate Professor, Department of Psychology, University of Calcutta. (C) 2015 I A Karmakar, S Raychaudhuri; licensee IJIP. This is an Open Access Research distributed under the terms of the Creative Commons Attribution License (http://creativecommons.org/licenses/by/2.0), which permits unrestricted use, distribution, and reproduction in any Medium, provided the original work is properly cited.
} 


\section{Loneliness \& Depression: An Urban Syndrome?}

networks of social relationships are smaller or less satisfying than the person desires'. People can experience loneliness for countless reasons and many life events like the lack of friendship during childhood and adolescents, or the physical absence of meaningful people around the person. Simultaneously loneliness may be a symptom of a psychological predicament. Social connectedness is increasingly being recognised as an essential component for well being of the majority (Searle, 2008).

Depression and loneliness are distinct but closely related. On the one hand, negative perception of one's social relationship (loneliness) may form the basis for the development of dysthymic mood and on the other hand, that may contribute to impairments in social relationship and thus to feelings of loneliness. Depression or major depressive disorder (also known as unipolar depression) is mental disorder characterised by an importunate and omnipresent low mood that is accompanied by loss of self esteem and by a loss of interest or pleasure in commonly enjoyable activities. Depression is major cause of morbidity worldwide. It affects 121 million people globally and is responsible for 8, 50,000 deaths per year (World Mental Survey Initiative, 2011). Based on comprehensive interviews with over 89,000 people the results show that $15 \%$ of the population in affluent countries (compared to $11 \%$ for low/ middle income countries) are likely to acquire depression over their life span. Major Depressive Episodes (MDEs) were elevated in high income countries (28\% compared to $20 \%$ ) and were especially high (over $30 \%$ ) in France, The Netherlands and United states. The country with lowest incidence was China at $12 \%$ but in contrast MDEs were very common in India (almost 36\%)(WMH Survey Initiative, 2011). In India Nandi et al (2000) compared the prevalence of depression in the same catchment area after 20 years (First in 1972 and then in 1992) and reported that the prevalence of depression increased from 49.93 cases to 73.97 cases per 1000 population. Even though in the current age of rapid change in living styles, life expectancy and sense of society or community, more and more people are suffering depression and loneliness, not much research has been conducted to observe urban - rural differences in depression and loneliness. In the state of Tamilnadu, India, Selvaraj and Ganadevan (2012) found that students residing at urban area reported to be lonelier that those residing in rural areas. The study conducted by McGee et al (2005) comparing the loneliness levels of old and adults residing in urban and rural areas of Ireland found that older adults residing in rural areas were lonelier than those residing in Urban areas. Study by Probst et al (2006) found the prevalence of depression to be slightly higher in residents of rural areas compared to urban areas. In the study conducted by Wang (2004) in Canada found that participants in rural areas had lower prevalence of MDE than those in urban areas.

Briefly, existing literature and research findings demonstrate that both loneliness and depression is associated with individual, familial and social factors. But there has been a paucity of research concerning these factors. Almost all the research has been exclusively confined to Western societies, where the social structures and way of life is much different from what that is in the Orient such as India. Furthermore, there has been a serious lack of research concerning loneliness and depression in the adult population. In this juncture of rapid industrialisation and urbanisation when social values are fast changing and families are disintegrating with more and 
more people living alone, whether feelings of loneliness and depression is more intense in urban residence might pose an engaging question.

The aim of the study was to observe whether severity of subjective feelings of loneliness and depression varies across habitat (urban compared to rural), both in clinically depressed as well as nonclinical sample i.e if people suffering from MDD living in urban residence differs from people suffering from MDD living in rural residence in subjective feelings of loneliness and depression, as well as if these subjective feelings differed across 'psychologically healthy' people of urban and rural residence.

\section{MATERIALS AND METHODS}

\section{Plan of Work}

For the present study, the total sample was divided into two broad subgroups viz. 'clinically depressed' group and 'nonclinical group'. Both the groups had 160 participants each (40 rural men, 40 rural women, 40 urban men and 40 urban women).These two groups had two subdivisions in terms of the habitat of the participants i.e. urban or rural. The participants were men and women of the age range 20-38 years residing in urban or rural areas of West Bengal. The participants selected in the 'clinically depressed' group were suffering from major depressive disorder (MDD) for less than 2 years (Diagnosis of Major Depressive Disorder was made using the DSM-IV-TR criteria) and those in the 'nonclinical' group were screened on the basis of GHQ-28(Goldberg and Miller, 1979) score and thus were not suffering from any psychiatric illness. Those with history of psychiatric illness were excluded from the nonclinical group. After obtaining informed consent from the participants, the information schedule (to obtain family and personal history), Beck Depression Inventory (Beck et al 1961; to measure severity of subjective feelings of depression) and Revised UCLA Loneliness scale (Russell, Peplau and Cutrona, 1980; to measure severity of subjective feelings of loneliness) were administered.

\section{Sample characteristics}

Participants in the 'clinically depressed' group were selected from the Psychiatry department of NRS Medical College, Kolkata. The urban participants were residents of urban and sub-urban areas of Greater Metropolitan Kolkata and the rural participants were residents of villages (beyond district and block towns) of the districts of Nadia, Howrah, the 24 Parganas, Hoogly, Burdwan, East and West Midnapore.

In the 'nonclinical' group, the urban participants were residents of urban areas of Kolkata and Howrah and the rural participants were residents of the village of Sapdaha (Panchayet- Garanga, Block-Garbeta, District-West Midnapore).

The participants of the two groups (Clinical and non-clinical) were matched on the basis of age, socio-economic status, educational status. The mean age of the participants of the clinical group 
was 28.2 years whereas the mean age of the participants of the non-clinical group was 28.9 years.

The participants who were suffering from MDD for more than 2 years and those who had any co-morbid psychiatric illness along with MDD were not included in the work. Participants outside the age range of 20-38 years, monthly income outside the range of Rs10,000-20,000 per month, resident of their respective habitat for less than 3 years, education less than grade 6 were not included in the work.

\section{Statistical Analysis}

Descriptive statistics (Mean \& Standard Deviation) and Analysis of Variance was conducted using SPSS v16.

\section{RESULTS}

The results of the study indicated that the 'clinically depressed' group was much lonelier than the 'nonclinical' group. As shown by descriptive statistical analysis, the urban participants suffering from Major Depressive Disorder (MDD) made the loneliest group (Mean score on measure of subjective feelings of loneliness=48.8), followed by rural participants suffering from MDD (Mean score=40.05), 'nonclinical' urban participants (Mean score=38.5) and 'nonclinical' rural participants (Mean score=26.05). Overall, the urban group reported much higher feelings of loneliness $($ Mean $=43.65)$ than the rural group $($ Mean=33.05).

Analysis of variance showed that the urban and rural group differed significantly in their subjective feelings of loneliness and depression both in the clinical and non-clinical group, as well as when clinical and non-clinical groups were taken together.

TABLE 1: Significance of difference between the urban and rural group in the clinical and the non-clinical group, with respect to subjective feelings of loneliness and depression

\begin{tabular}{|c|c|c|c|c|c|c|c|c|c|c|c|c|}
\hline \multirow{3}{*}{ Group } & \multicolumn{4}{|c|}{$\begin{array}{l}\text { Clinically } \\
\text { depressed }\end{array}$} & & & \multicolumn{4}{|c|}{ Nonclinical } & \multirow{3}{*}{$\begin{array}{l}\text { F } \\
\text { valu } \\
\text { e } \\
\end{array}$} & \multirow{3}{*}{$\begin{array}{l}\mathbf{P} \\
\text { value }\end{array}$} \\
\hline & \multicolumn{2}{|c|}{ Urban } & \multicolumn{2}{|c|}{ Rural } & \multirow[t]{2}{*}{$\begin{array}{l}\text { F } \\
\text { value }\end{array}$} & \multirow[t]{2}{*}{$P$ value } & \multicolumn{2}{|c|}{ Urban } & \multicolumn{2}{|c|}{ Rural } & & \\
\hline & M & S.D & M & $\begin{array}{l}\text { S. } \\
\text { D }\end{array}$ & & & M & $\begin{array}{l}\text { S. } \\
\text { D }\end{array}$ & M & $\begin{array}{l}\text { S. } \\
\text { D }\end{array}$ & & \\
\hline $\begin{array}{l}\text { Lonelin } \\
\text { ess }\end{array}$ & $\begin{array}{l}48 . \\
8\end{array}$ & $\begin{array}{l}12 . \\
589\end{array}$ & $\begin{array}{l}40 \\
.0 \\
5\end{array}$ & $\begin{array}{l}7 . \\
07 \\
3\end{array}$ & $\begin{array}{l}25.43 \\
* *\end{array}$ & .000 & $\begin{array}{l}38 . \\
5\end{array}$ & $\begin{array}{l}4.3 \\
71\end{array}$ & $\begin{array}{l}26 . \\
05\end{array}$ & $\begin{array}{l}3.1 \\
87\end{array}$ & $\begin{array}{l}29.9 \\
6 * *\end{array}$ & .000 \\
\hline $\begin{array}{l}\text { Depress } \\
\text { ion }\end{array}$ & $\begin{array}{l}34 . \\
15\end{array}$ & $\begin{array}{l}5.5 \\
18\end{array}$ & $\begin{array}{l}31 \\
.9\end{array}$ & $\begin{array}{l}5 . \\
21\end{array}$ & $3.91 *$ & .05 & $\begin{array}{l}7.7 \\
5\end{array}$ & $\begin{array}{l}2.6 \\
93\end{array}$ & 4.9 & $\begin{array}{l}2.8 \\
26\end{array}$ & $4.1^{*}$ & .003 \\
\hline
\end{tabular}


TABLE 2: Significance of difference between the urban and rural group with respect to subjective feelings of loneliness and depression

\begin{tabular}{|l|l|l|l|l|l|l|}
\hline & \multicolumn{2}{|l|}{ Urban } & \multicolumn{2}{l|}{ Rural } & F value & $\begin{array}{l}\text { P } \\
\text { value }\end{array}$ \\
\hline & M & S.D & M & S.D & & \\
\hline Loneliness & 43.65 & 10.664 & 33.05 & 8.895 & $26.56^{* *}$ & .000 \\
\hline Depression & 20.95 & 14.038 & 18.4 & 12.284 & $3.86^{*}$ & .004 \\
\hline
\end{tabular}

**- significant at .01 level., *-significant at .05 level. SD- Standard Deviation M-Mean

\section{DISCUSSIONS}

The results indicated that feelings of both loneliness and depression are more intense in urban residents than rural residents. Urban residents suffering from MDD were the loneliest. In the nonclinical group, too, urban residents reported greater feelings of loneliness and depression than rural residents. Social connectedness is increasingly being recognised as an essential component of well-being for most people. Humans are essentially collective in nature and nobody can live without a social web. In an era characterized by population aging, more and more people are living longer and alone. People living in single person and single parent households are twice as likely to experience loneliness as people living in couple households (Baker, 2010). NSSO of India in 2004 indicated that 1.23 million men and 3.68 million women are living alone and face loneliness (Jeyalakshmi and Chakrabarti, 2011).

Victor et al (2009), in their study found that one of the prime causes of loneliness in the rise in the number of people living alone, perhaps one of the biggest change in terms of people's social relations. While only $18 \%$ of people lived alone in 1971 in the U.K, by 2006, this number had increased to 29\% (Victor et al, 2009). This increase in number of people living alone is in the rise even in the developing countries. Importantly, the Victor et al study also discovered an often overlooked spatial aspect to social isolation, whereby either through increasing mobility, dispersion, residence in 'separate' accommodation, or because of declining community, people came to feel socially isolated where they lived. The notion of what makes a community is in a state of flux: communities that were tied to localities are declining, but communities based on common interest such as environmentalism are thriving. Sociologists articulate that the old notion of community is more fluid and open. Fewer people pronounce that they belong to traditional community yet not everyone feels part of the new community taking shape. A survey by University of Sheffield for the BBC in 2008 tracked 'anomie', a sense of not belonging to a community and concluded that a sense of community had been weakening over the past 30 years. As early as 1950 the US sociologist Robert Weiss found that residence of transient communities lacked long-term relationships with friends and neighbours, as well as the benefits of living closer to older generations of their own families (Weiss, 1975). 


\section{Loneliness \& Depression: An Urban Syndrome?}

Interdependence was not always a conscious decision, rather a compulsion in the old rural society. For example, parental properties, as a norm, could not be divided until the death of parent; that made siblings to remain together till very late of their age resulting in a large joint family. Despite its many obvious advantages, physical or emotional security and economies of scale being the most obvious ones, the joint family system is collapsing. As market in modern societies started offering new job opportunities, which attracts young people out of their parental families, eventually landing in urban or industrial centre which has an atomistic society. Thus loneliness has become a social issue in contemporary societies.

Depression and loneliness are distinct but closely related, mutually reinforcing phenomena. On the one hand, negative perception of one's social relationship (loneliness) may form the basis for the development of depressive symptoms, and on the other hand depression may contribute to impairments in social relationship (Joiner \& Timmons, 2009) and hence to feeling of loneliness. The initiation and maintenance of social relationships are important to life satisfaction, and numerous studies have indicated that loneliness is associated with symptoms of poor mental health such as depression (Heinrich and Gullone, 2006). Finally, as the depression is maintained or deepened, social connections are further weakened. The depressed individual desires the social contact, yet lacks the behavioural activation to address the situation, leading to a discrepancy between the desired and achieved levels of interpersonal relationships, that is, loneliness. As found by Wang (2004), participants in rural areas had a lower prevalence of MDEs than those in urban areas, even after controlling for marital status and working status.

As observed by Paykel et al (2000), rural residents have slightly better mental health than nonrural counterparts. The effects of geographical location on mental health of participants were neither significantly confounded nor modified by socioeconomic status, employment status or household income. A study conducted by Sundquist et al (2004) found a linear association between increasing population density and first-admission rate for depression. Middleton et al (2003) found suicide rates to be significantly higher in urban areas of England and Wales than in rural areas.

More and more people live alone in urban societies than in rural societies. Mijuskovic (1992) distinguished two models of human organisation, namely the organic community and the atomistic society. In organic community, the individual greatly relies on community for support, a sense of belonging, reciprocal sharing with others and one's sense of identity. In atomistic society, individual achievement and competitive, impersonal social relations, which make alliances with each other more difficult, are encouraged. They were described by Mijuskovic (1992) as regarding relationships as contractual, external, and formal.

It is evident that urban India is fast changing and fitting into an atomistic society. Urban and rural areas differ in ways that encompass both the physical and social environments, ranging from factors such as access to education, employment, transport to leisure facilities, noise, crowding, rates of crime etc. 
It has long been noted that urban stressors like noise, crowding have adverse impact on physical health too, for example, hypertension and cardiovascular disease. Recent studies have noted correlation between depression and hypertension as well as other forms of cardiovascular disease (Scalco et al 2005). The greater intensity of depressive symptomatology in urban participants may be attributed also to greater stress related to housing, work, marriage, child rearing and security, combined with inadequate resources (e.g. social support) to cope with the stressors. There is higher concentration of poverty in city centres and higher rates of socio-cultural disintegration (e.g. in the form of separation, divorce). Migration from rural to urban areas, too, might make urban life difficult.

Thus, in conclusion, this study indicate that there is a significant effect of habitat in subjective feelings of loneliness and depression in adults. Urban residents were found to be significantly lonelier and more depressed than rural residents. Community psychological intervention might be aimed at this.

However, this study has some limitations as well. To obtain data, only self-report measures have been used. More 'direct' and elaborate techniques can be used along with self-report measures to corroborate the data obtained from self-report measures. More detailed work is needed to explore the factors that reinforces and sustains loneliness and depression in urban residents. Also, rather than the simple dichotomy of urbanicity and rurality, varying levels of urbanicity might be of interest.

\section{REFERENCES}

Beck, A.T., Ward, C.H., Mendelson, M., Mock, J., \& Erbaugh, J. (1961) An inventory for measuring depression. Archives of general psychiatry, 4, 561-571.

Ernst, J. M. and Cacioppo, J. T., 1999. 'Lonely hearts: psychological perspectives on loneliness' Applied and Preventive Psychology 8 (1), 1-22.

Heinrichs, L.M., \& Gullone, E. (2006). The clinical significance of loneliness: a literature review, Clinical Psychology Review, 26.

Jeyalakshmi S,Chakrabarti S, Gupta N. Situation analysis of the elderly in India. Central Statistics Office, Ministry of Statistics and Programme Implementation, Government of India document,June2011.

Joiner, T. E., Jr. \& Timmons, K. A. (2009): Depression in its interpersonal context. In I. H. Gotlib \& C. L. Hammen (Eds.) Handbook of Depression (2nd ed., pp. 322-339). New York: Guilford Press.

Lauder,W., Mummery, K., Jones, M., \& Caperchione,C. 2006. A Comparison of health behaviours in lonely and non-lonely populations. Psychology, Health \& medicine, 11, 233-245. 


\section{Loneliness \& Depression: An Urban Syndrome?}

McGee, H., Hanlon, A. O., Barker, M et al (2005) One Island - two system. A comparison of health status and health and social services used by community - dwelling older people in the Republic of Ireland and Northern Ireland. Dublin. The Institute of Public Health In Ireland.

Middleton,N., Gunnell,D.,Frankel,S.(2003). Urban-rural differences in suicide trends in young adults: England and Wales, 1981-1998. Social science and medicine, 57, pp 1183-1194

Mijuskovic, B. Organic communities, atomistic societies and loneliness. J. Soc. And Soc. Welfare 19, 147. (1992)

Nandi, D. N., Banerjee, G., Mukherjee, S. P. Ghosh, A., Nandi, P.S., Nandi, S. Psychiatric Morbidity of a rural Indian community changes over a 20 years interval. British Journal of Psychiatry. 2000; 176-351-6.

Paykel, E.S., Abbott,R., Jenkins, R.,(2000) Urban-rural mental health differences in Great Britain: findings from the national Morbidity survey. Psychological Medicine,30,pp 269280.

Peplau L, Perlman D. Perspectives on loneliness. In: Peplau L, Perlman D, eds. Loneliness: A sourcebook of current theory, research, and therapy. New York: Wiley; 1982.

Probst J.C Laditka SB, Moore CG, Harun N, Powell MP, Baxley EG. Fam Med. 2006 Oct; 38(9):653-60.

Ronald C Kessler, Sergio Aguilar-Gaxiola, Jordi Alonso, Somnath Chatterjee, Sing Lee, Johan Ormel, T Bedirhan Ustun and Phillip S Wang. The Global burden of mental disorders: A update from the WHO world mental health (WMH) surveys. Epidemiol Psichiatr Soc. 2009 Jan-Mar; 18 (I):23 to 33.

Russell, D., Peplau, L. A., \& Cutrona, C. E. (1980). The revised UCLA loneliness scale: Concurrent and discriminant validity evidence. Journal of Personality and Social Psychology, 39, 472-480.

Scalco,A.Z., Scalco M.Z, Azul,J.B, Lotufo Neto F. Hypertension and depression. Clinics 2005; 60(3):pp241-50

Searle, B. (2008). Wellbeing: In Search of a Good Life? Bristol: The Policy Press.

Selvaraj, A and R.Gnanadevan, R. Golden Research Thoughts Vol.II Sept 2012

Sundquist,K., Frank,G, \& Sundquist, J. (2004) Urbanisation and incidence of psychosis and depression. Follow-up study of 4.4 million women and men in Sweden. British Journal of Psychiatry, 184, pp293-298 


\section{Loneliness \& Depression: An Urban Syndrome?}

Wang, J.L, Rural-urban differences in the prevalence of major depression and associated impairment. Social Psychiatry and psychiatric Epidemiology 2004 Vol.39,Issue 1, pp 1925.

Weiss, R. (1975) Loneliness: The experience of emotional and social isolation. Boston: MIT Press.

Victor, C., Scambler, S., \& Bond, J. The Social World of Older People: Understanding Loneliness \& Social isolation in Later Life. Open University Press. 2009. 